\title{
Evaluation of the oblique fissure on lateral chest radiographs in coal workers pneumoconiosis
}

\author{
Kacar $\mathrm{D}^{1}$, Dogan $\mathrm{A}^{2}$, Barut $\mathrm{C}^{1}$ \\ Department of Anatomy, School of Medicine, Bulent Ecevit University, Zonguldak, Turkey. \\ cagbarut@yahoo.com
}

\begin{abstract}
Objective: The oblique fissure separates the upper lobe from the lower lobe in the left lung and the upper lobe from the lower and middle lobes in the right lung. The aim of the present study was to compare the projection of the oblique fissure observed on lateral chest radiographs of retired coal mine workers who had coal worker's pneumoconiosis (CWP) with that of healthy men.

Materials and methods: The study included 120 men divided into three groups: retired coal miner patients diagnosed with CWP (group 1), men $\geq 38$ years of age with no CWP (group 2, first control group), and men $\leq 37$ years of age with no CWP (group 3, second control group). The projection of the oblique fissure observed on lateral chest radiographs (left side) were evaluated using geometric morphometrics. Geometric morphometric analysis of each sample was performed using 11 pre-specified landmarks designated on X-ray images, using tpsDig2 software. A text file containing the landmark coordinates of the 120 samples was created, and the data in the text file was statistically analyzed using Morpheus software.

Results: The projection of the oblique fissure differed significantly between the CWP patients and the control groups $(p<0.05)$.

Conclusion: We suggest that the difference in the projection of the oblique fissure between men with and without CWP was attributable to a protrusion in the fissure caused by nodules that developed in the lungs of coal miners after years of dust inhalation (Tab. 4, Fig. 4, Ref. 30). Full Text in PDF www.elis.sk.

Key words: lateral chest radiograph, oblique fissure, CWP, geometric morphometrics, landmark.
\end{abstract}

The International Labor Organization has defined pneumoconiosis as the accumulation of dust in the lungs and secondary tissue reactions to its presence (1). Larger inhaled dust particles are retained in the nose, trachea, or large bronchi by respiratory mechanisms. However, dust particles with diameters of 1-5 $\mu \mathrm{m}$ can reach the pulmonary parenchyma. As the dust load in the parenchyma increases with continued dust inhalation, particles accumulate in the alveoli (2).

The oblique fissure separates the upper lobe from the lower lobe in the left lung and the upper lobe from the lower and middle lobes in the right lung. Lateral examination of the lungs shows that the oblique fissure originates at the level of the fourth thoracic vertebra posteriorly and extends forward in an oblique manner in both lungs. Because the left lung is longer than the right lung, the fissure extends more vertically on the left (3). The aim of the present study was to compare the projection of the oblique fissure on lateral chest radiographs of men who retired from coal mining following the development of coal worker's pneumoconiosis (CWP) and that of healthy control subjects, using geometric morphometrics.

${ }^{1}$ Department of Anatomy, School of Medicine, Bulent Ecevit University,
Zonguldak, Turkey, and ${ }^{2}$ Department of Anthropology, Faculty of Arts and
Sciences, Ahi Evran University, Kirsehir, Turkey

Address for correspondence: C. Barut, MD, PhD, Department of Anatomy, School of Medicine, Bulent Ecevit University, 67600, Kozlu, Zonguldak, Turkey .

Phone: +90.532.4638471, Fax: +90.372.2610264

\section{Materials and methods}

The study analyzed lateral chest radiographs obtained from 120 men, who were divided into three groups: patients diagnosed with CWP while working in coal mines (group $1 ; n=62$ ); men $\geq 38$ years of age without CWP (group 2, first control group; $n=31$ ); and men $\leq 37$ years of age without CWP (group 3, second control group; $\mathrm{n}=27$ ).

Lateral chest radiographs (=left side X-rays) were taken at a distance of $120 \mathrm{~cm}$ and at the deep inspiration phase using the 120 $\mathrm{KVp}$ technique, with the subject's arms above his head and with the left side of his chest cage in complete contact with the X-ray cassette (4). The radiographs were magnified to a maximum level on a PC screen before the measurements were made. All lateral radiographs were screened, small regions were investigated, and all structures on each radiograph were assessed.

The levels of the thoracic vertebrae were determined according to anatomical landmarks as follows: the jugular notch lies at the level of the second thoracic vertebra in relation to the vertebral column; the sternal angle (Angle of Louis) lies at the level of the intervertebral disc between the fourth and fifth thoracic vertebrae; and the xiphosternal joint lies at the level of the ninth thoracic vertebra relative to the vertebral column $(3,5)$.

In group 1, the X-rays revealed widespread dense regions, and these fissures were screened at higher magnification and in smaller regions than in the other two groups. Following this assessment, the lateral chest X-rays were evaluated using geometric morpho- 


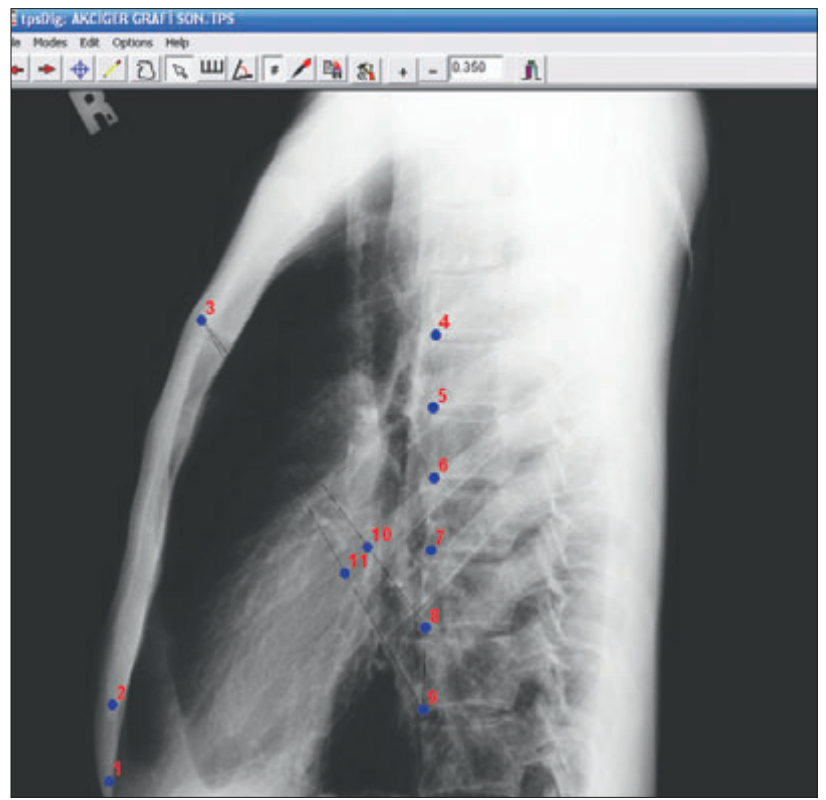

Fig. 1. Landmarks designated in the files created by TpsDig and TpsUtil software. Anatomical localizations of the landmarks are described in Table 1.

metrics to measure deviations in the fissure, as this technique is sensitive enough to allow minimal changes to be measured. Geometric morphometrics have been reported to be more effective than conventional morphometry (6), and the analysis has been used together with linear measurements (7).

Geometric morphometric measurements were taken from files of the 120 lateral chest X-rays that were created using tpsUtil software (8). TpsDig2 software (8) was used to mark 11 landmark reference points, nine on bones and two (landmarks 10 and 11) related to soft tissue structures (Fig. 1) (Tab. 1), for each X-ray. A text file containing the reference point coordinates of the 120 samples was created.

Using the $\mathrm{x}, \mathrm{y}$ coordinate data obtained from the 11 landmarks, intergroup variation was evaluated, and intergroup shape differences were investigated using deformation grids. Data in the text file were statistically analyzed using Morpheus software (9). The landmark configurations were scaled, translated, and ro-

Tab. 1. Anatomical localization of the landmarks.

\begin{tabular}{ll}
\hline Landmarks & Anatomical localization \\
\hline 1 & Lower end of the xiphoid process \\
2 & Middle point of the xiphosternal joint \\
3 & The peak of the angle of Louis \\
4 & Anterior-lower end point of the body of the T4 vertebra \\
5 & Anterior-lower end point of the body of the T5 vertebra \\
6 & Anterior-lower end point of the body of the T6 vertebra \\
7 & Anterior-lower end point of the body of the T7 vertebra \\
8 & Anterior-lower end point of the body of the T8 vertebra \\
9 & Anterior-lower end point of the body of the T9 vertebra \\
10 & The interception of the line joining landmarks no 3 and 8 \\
11 & with the oblique fissure \\
& The interception of the line joining landmarks no 3 and 9 \\
\hline
\end{tabular}

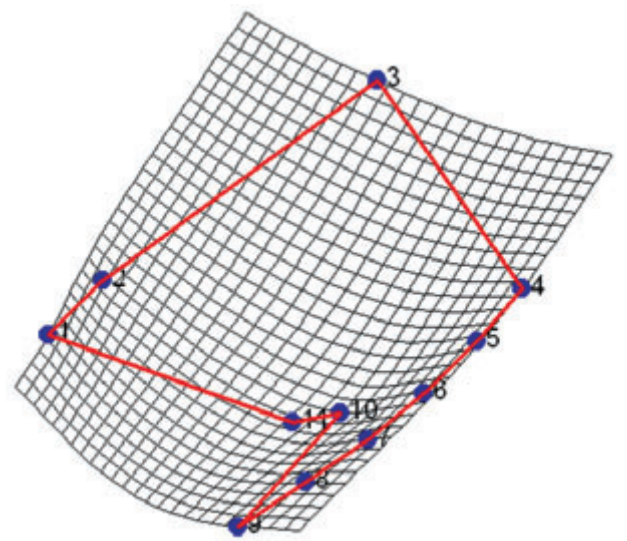

Fig. 2. Deformation grid comparison between group 1 (CWP) and control group 2. Anatomical localizations of the landmarks are described in Table 1.

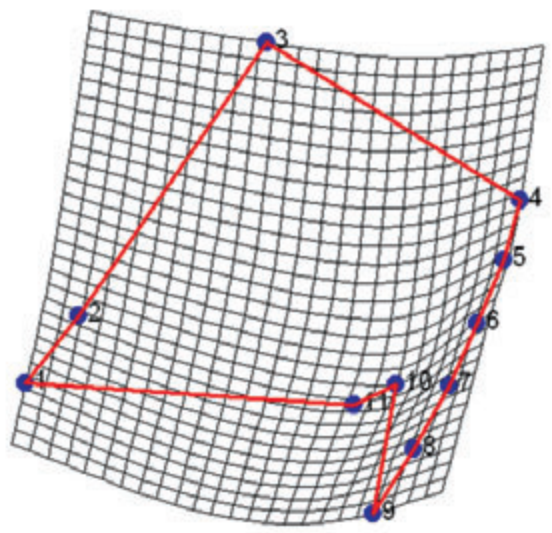

Fig. 3. Deformation grid comparison between group 1 (CWP) and control group 3. Anatomical localizations of the landmarks are described in Table 1.

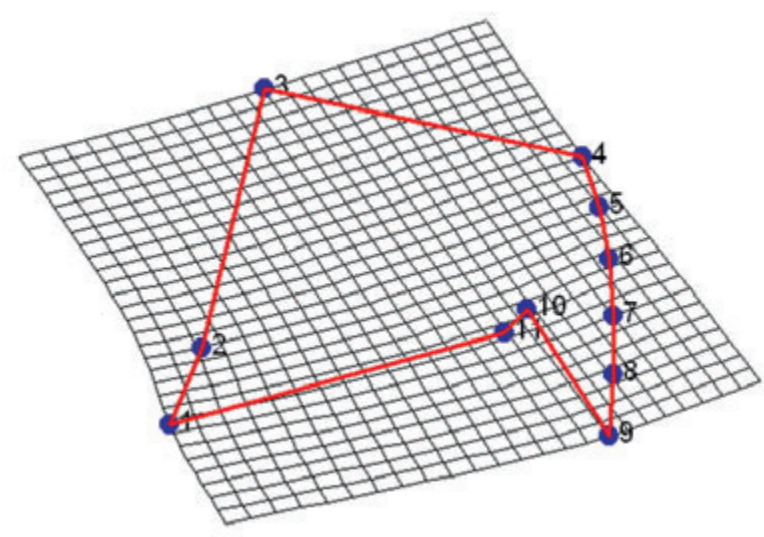

Fig. 4. Deformation grid comparison between control groups 2 and 3. Anatomical localizations of the landmarks are described in Table 1.

tated against the consensus configuration, using the generalized least-squares (GLS) Procrustes superimposition method (10). In this way, differences in landmark coordinates caused by image position or size were standardized. Multivariate analysis of vari- 
Tab. 2. Comparison of the coordinates of landmarks 10 and 11 on the $\mathrm{x}$-axis.

\begin{tabular}{lcccc}
\hline Variable & $\begin{array}{c}\text { GROUP-1 } \\
\text { CWP } \\
\mathrm{n}=62\end{array}$ & $\begin{array}{c}\text { GROUP-2 } \\
\text { CONTROL-Y } \\
\mathrm{n}=31\end{array}$ & $\begin{array}{c}\text { GROUP-3 } \\
\text { CONTROL-G } \\
\mathrm{n}=27\end{array}$ & $\mathrm{p}$ \\
\hline $\mathrm{X} 10$ & $0.046 \pm 0.039$ & $0.062 \pm 0.028$ & $0.057 \pm 0.027$ & $\mathrm{p}>0.05$ \\
$\mathrm{X} 11$ & $0.013 \pm 0.036$ & $0.026 \pm 0.03$ & $0.018 \pm 0.029$ & \\
\hline
\end{tabular}

Tab. 3. Comparison of the coordinates of landmarks 10 and 11 on the y-axis.

\begin{tabular}{lcccc}
\hline Variable & $\begin{array}{c}\text { GROUP-1 } \\
\text { CWP } \\
\mathrm{n}=62\end{array}$ & $\begin{array}{c}\text { GROUP-2 } \\
\text { CONTROL-Y } \\
\mathrm{n}=31\end{array}$ & $\begin{array}{c}\text { GROUP-3 } \\
\text { CONTROL-G } \\
\mathrm{n}=27\end{array}$ & $\mathrm{p}$ \\
\hline Y10 & $0.012 \pm 0.024$ & $-0.005 \pm 0.023$ & $-0.005 \pm 0.022$ & $<0.001$ \\
Y11 & $-0.032 \pm 0.032$ & $-0.053 \pm 0.028$ & $-0.058 \pm 0.029$ & \\
\hline
\end{tabular}

ance (MANOVA) was performed to evaluate differences among groups, and pairwise comparisons were performed to assess the significance of between-group differences.

\section{Results}

Evaluation of the deformation grids (Figs 2, 3, and 4) revealed that the highest level of deformation occurred between groups 1 and 2 , and most of the variations were observed at landmarks 6 , 7, 8, 9, 10 and 11 (Fig. 2). The deformations at landmarks 6, 7, 8 and 9 can be explained by the advanced age of patients with CWP and bone tissue deformations that occurred over time in the body of the vertebra. Deformations at landmarks 10 and 11 indicated differences in the oblique fissure projection.

To fulfill the primary objective of our study, only the coordinate variables of the oblique fissure landmarks $\left(\mathrm{Y}_{10}, \mathrm{Y}_{11}\right.$ and $\left.\mathrm{X}_{10}, \mathrm{X}_{11}\right)$ were assessed. The analysis of the $X_{10}$ and $X_{11}$ variables showed no statistically significant differences among groups $(p>0.05)$ (Tab. 2), whereas the analysis of the $Y_{10}$ and $Y_{11}$ variables revealed a statistically significant difference $(p<0.001)$ (Tab. 3). Further analysis indicated that both variables contributed to this difference $\left(p=0.001\right.$ for each variable). In pairwise analyses, the $Y_{10}$ and $\mathrm{Y}_{11}$ variables for group 1 differed significantly from those for control groups 2 and 3, but there was no difference in the $\mathrm{Y}_{10}$ or $\mathrm{Y}_{11}$ variable between groups 2 and 3 (Tab. 4).

\section{Discussion}

At present, computed tomography (CT) and high resolution computed tomography (HRCT) provide the most detailed information and are considered to be the best techniques for lung assessment (11-16). CT and HRCT are commonly used to evaluate pulmonary fissures (17-21). HRCT is useful for the noninvasive diagnosis of dust-associated lung disease (22). Nevertheless, conventional chest radiography has several advantages over CT and HRCT. After a complete medical history, conventional chest radiography is one of the initial steps used for diagnosing dust-associated lung diseases because of its low cost, low level of exposure to radiation, and wide range of uses $(22,23)$. Several studies have used conventional chest X-rays to study fissures; for example, Gülekon et al (24) and Abiru et al (25) investigated the incidence of accessory fissures on lung X-rays using posterior-anterior (PA) direct X-ray assessment of the fissure.

The present study used lateral chest X-rays to detect deviations in projections of the oblique fissure that were caused by nodules resulting from coal dust inhalation. Lateral chest X-rays are thought to detect these changes because dust, which does not normally exist in the lungs, occupies space. The lungs of coal workers contained 40-60 grams of total dust (approximately 20 $\%$ of the weight of the lungs) (26). Furthermore, most of the dust was located in the apicoposterior regions of the upper lobe of the lung, (27) reinforcing the idea that the excessive volume can cause deviations in the projection of the oblique fissure. A review of the literature found no similar studies with which we could compare our results. Although we found several studies on pneumoconiosis, most were related to the detection and classification of lung nodules and pleural thickening in the lungs, $(28,29)$ and some had investigated the correlation between respiratory function tests and the disease (30).

The coordinates of landmarks 10 and 11 of the oblique fissure projection in group 1 (CWP cases) were significantly different from those in control groups 2 and $3(\mathrm{p}<0.05)$, while the coordinates did not differ significantly between the two control groups. These results suggest that the deviations were a function of CWP (Tab. 4) and that age had no effect on the projection of the oblique fissure. In summary, our results indicate that lung nodule develop-

Tab. 4. Pairwise between-group comparisons of landmarks 10 and 11 on the y-axis.

\begin{tabular}{|c|c|c|c|c|c|c|c|}
\hline \multirow{2}{*}{ Variable } & \multirow{2}{*}{ Group } & \multirow{2}{*}{ Group } & \multirow{2}{*}{ Mean Difference } & \multirow{2}{*}{ Std. Error } & \multirow{2}{*}{$\mathrm{p}$} & \multicolumn{2}{|c|}{$\% 95$ Confidence interval for Difference } \\
\hline & & & & & & Lower Bound & Upper Bound \\
\hline \multirow{6}{*}{ Y10 } & \multirow[t]{2}{*}{1} & 2 & 0,017 & 0,005 & 0,001 & 0,007 & 0,027 \\
\hline & & 3 & 0,017 & 0,005 & 0,002 & 0,007 & 0,028 \\
\hline & \multirow[t]{2}{*}{2} & 1 & $-0,017$ & 0,005 & 0,001 & $-0,027$ & $-0,007$ \\
\hline & & 3 & 0,000 & 0,006 & 0,972 & $-0,012$ & 0,012 \\
\hline & \multirow[t]{2}{*}{3} & 1 & $-0,017$ & 0,005 & 0,002 & $-0,028$ & $-0,007$ \\
\hline & & 2 & 0,000 & 0,006 & 0,972 & $-0,012$ & 0,012 \\
\hline \multirow{6}{*}{ Y11 } & \multirow[t]{2}{*}{1} & 2 & 0,021 & 0,007 & 0,002 & 0,008 & 0,034 \\
\hline & & 3 & 0,026 & 0,007 & 0,000 & 0,013 & 0,040 \\
\hline & \multirow[t]{2}{*}{2} & 1 & $-0,021$ & 0,007 & 0,002 & $-0,034$ & $-0,008$ \\
\hline & & 3 & 0,005 & 0,008 & 0,526 & $-0,011$ & 0,021 \\
\hline & \multirow[t]{2}{*}{3} & 1 & $-0,026$ & 0,007 & 0,000 & $-0,040$ & $-0,013$ \\
\hline & & 2 & $-0,005$ & 0,008 & 0,526 & $-0,021$ & 0,011 \\
\hline
\end{tabular}


ment as a result of inhaled dust may in time cause a deviation in the projection of the oblique fissure.

\section{Conclusion}

Projections of the oblique fissure in men with CWP (group 1) were significantly different from those of healthy controls of similar (group 2) and younger age (group 3). We attributed this difference to a protrusion in the fissure caused by the volume of inhaled dust. These findings indicate that although no test is available for early diagnosis of pneumoconiosis and there is no cure at present, it would be beneficial to regularly monitor environmental dust measurements, provide workers with appropriate health-related information, and schedule examinations at regular intervals.

\section{References}

1. Stellman JM. Encyclopedia of occupational health and safety. Geneva; International Labor Office, 1998.

2. Erk M. Gögüs hastalıkları. Istanbul; Istanbul University, 2001: 945-948.

3. Standring $\mathbf{S}$ (Ed). Gray's anatomy. The anatomical basis of clinical practice. 40th ed. New York; Churchill Livingstone Elsevier, 2008: 917-993.

4. Ödev K (Ed). Toraks radyolojisi. Istanbul; Nobel Medical Publishing, 2005: 15-77.

5. Arinci K, Elhan A (Eds). Anatomi. 4th ed. Ankara; Güneş Publishing, 2006; 68: 301-309.

6. Kekecoglu M, Bouga M, Soysal MI, Harizanis P. Morphometrics as a tool for the study of genetic variability of honey bees. J Tekirdag Agriculture Faculty 2007; 4 (1): 7-16.

7. Kacar D, Cakmak F, Dogan A, Sevinc O, Barut C. Evaluation of lingual frenulum using geometric morphometrics. Int J Morphol 2011; 29 (2): 313-317.

8. Rohlf FJ. TPS series. Department of ecology and evolution, State University of New York, Stony Brook, New York. 2001. Available from: http://life.bio.sunysb.edu/morph/

9. Slice D Morpheus et al. Platform-independent software for morphometric analysis. Department of ecology and evolution, State Univ. New York, Stony Brook. 1999. Available from: http://www.morphometrics.org/morpheus.html

10. Bookstein FL. Morphometric tools for landmarkdata, New York: Cambridge University Press, 1991.

11. Gevenois PA, Pichot E, Dargent F, Dedeire S, Vande WR, De Vuyst P. Low-grade coal worker's pneumoconiosis. Comparison of CT and chest radiography. Acta Radiol 1994; 35 (4): 351-356.

12. Takahashi K, Thompson B, Stanford $W$ et al. Visualization of normal pulmonary fissures on sagittal multiplanar reconstruction MDCT. AJR Am Roentgenol 2006; 187 (2): 389-397.

13. Zhang L, Hoffman EA, Reinhardt JM. Atlas-driven lung lobe segmentation in volumetric X-ray CT images. IEEE Trans Med Imaging 2006; 25 (1): $1-16$.
14. Glazer HS, Anderson DJ, DiCroce JJ et al. Anatomy of the major fissure: evaluation with standard and thin-section CT. Radiology 1991; 180 (3): 839-844.

15. Akira M. Uncommon pneumoconioses: $\mathrm{CT}$ and pathologic Findings. Radiology 1995; 197 (2): 403-409.

16. Kurihara Y, Matsuoka S, Yagihashi K, Yakushiji YK, Nakajima Y. Vertical fissure: computed tomographic observation and correlation with chest radiography. Radiat Med 2008; 26 (3): 129-132.

17. Wangl J, Bekte M, Ko JP. Shape-based curve growing model and adaptive regularization for pulmonary fissure segmentation in CT. Med Image Anal 2006; 10 (4): 530-547.

18. Bates AW. Variation in pulmonary fissures: Incidence in fetal postmortem examinations and a review of significant extrapulmonary structural abnormalities in sixty cases. Pediatric and Developmental Pathology 1998; 1 (4): 289-294

19. Otsuji H, Uchida H, Maeda $M$ et al. Incomplete interlobar fissures: bronchovascular analysis with CT. Radiology 1993; 187 (2): 541-546.

20. Lubner MG. The incomplete fissure sign. Radiology 2008; 247 (2): 589-590.

21. Modgil V, Das S, Suri R. Anomalous lobar pattern of right lung: A case report, Int J Morphol 2006; 24 (1): 5-6.

22. Blum T, Kollmeier J, Ott S, Serke M, Schönfeld N, Bauer T. Computed tomography for diagnosis and grading of dust-induced occupational lung disease. Curr Opin Pulm Med 2008; 14 (2): 135-140.

23. Hering KG. Significance of radiology for occupational and environmental lung diseases. Rofo 2006; 178 (4): 375-377.

24. Gülekon IN, Barut C, Turgut HB. The incidence and appearance of accessory fissures detected on plain chest radiographs. Morfoloji Dergisi 1999; 7 (2): 40-45.

25. Abiru H, Ashizawa K, Hashmi R, Hayashi K. Normal radiographic anatomy of thoracic structures: analysis of 1000 chest radiographs in Japanese population. Br J Radiol 2005; 78 (929): 398-404.

26. Nemery B, Bast A, Behr $\mathbf{J}$ et al. Interstitial lung disease induced by exogenous agents: Factors governing susceptibility. Eur Respir J 2001; 18 (32): $30-42$.

27. Hanley ME, Welsh CH (Eds). Current diagnosis \& treatment in pulmonary medicine (Eds: Uçan ES). Ankara: Güneş Publishing, 2005: 320-332.

28. Young RC, Rachal RE, Carr PG, Pres HC. Patterns of coal worker's pneumoconiosis in appalachian former coal miners. J Natl Med Assoc 1992; 84 (1): 41-48.

29. Albin M, Engholm G, Fröström $K$ et al. Chest $x$ ray films from construction workers: International Labour Office (ILO 1980) classification compared with routine readings. Br J Ind Med 1992; 49 (12): 862-868.

30. Bauer TT, Heyer CM, Duchna HW et al. Radiological findings, pulmonary function and dyspnea in underground coal miners. Respiration 2007; 74 (1): 80-87.

Received February 22, 2012. Accepted January 27, 2013. 